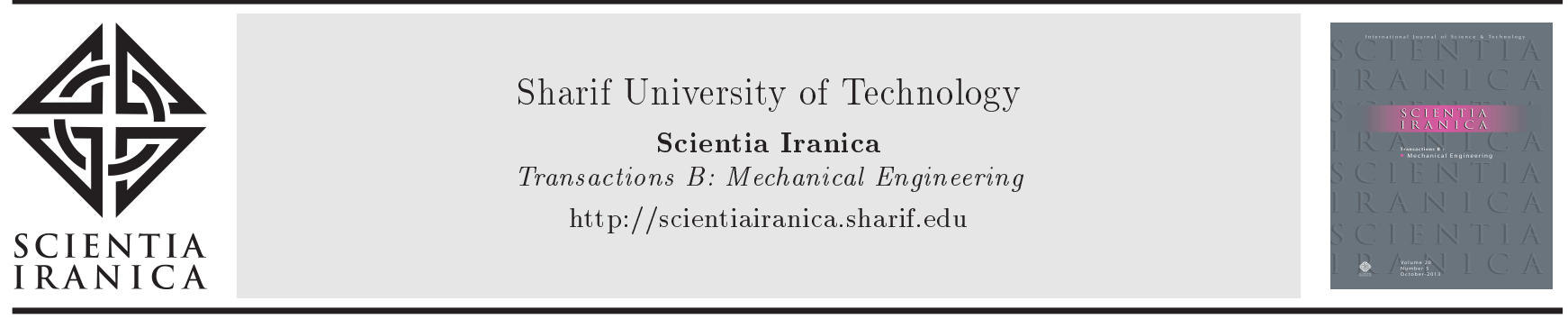

\title{
Computer modeling of the operating room ventilation performance in connection with surgical site infection
}

\author{
B. Sajadi ${ }^{a}$, M.H. Saidi ${ }^{b, *}$, and G. Ahmadi ${ }^{c}$ \\ a. School of Mechanical Engineering, College of Engineering, University of Tehran, Tehran, Iran. \\ b. School of Mechanical Engineering, Sharif University of Technology, Tehran, Iran. \\ c. Department of Mechanical and Aeronautical Engineering, Clarkson University, Potsdam, NY.
}

Received 15 November 2017; received in revised form 29 October 2018; accepted 31 December 2018

\section{KEYWORDS}

Operating Room

(OR);

Ultra-Clean

Ventilation (UCV)

system;

Computational Fluid

Dynamics (CFD);

Surgical Site Infection

(SSI).

\begin{abstract}
The primary source of surgical site infection is the deposition of flakes released from the exposed skin of surgical staff or the patient on the exposed surgical wound. In this study, a computational model for simulating airflow and thermal conditions in an operating room is developed, and transport and deposition of particulate contaminants near the wound are analyzed. The results show the formation of a thermal plume over the wound tissue, which is typically at a higher temperature than the surrounding. The thermal plume protects the wound from the deposition of contaminants. In addition, the computational model predicts an optimum value for the inlet air velocity that is mainly maintaining protective shielding effect of the wound thermal plume. The effects of particle size, surgical lights characteristics, and the presence of partitions on the optimum inlet air velocity are also studied. Based on the results, the formation of thermal plume over surgical lamps may easily disturb the airflow and impress the optimum inlet air velocity accordingly. Unfavorable obstruction effects of surgical lights can be reduced using welldesigned luminaries. The present study provides a better understanding of airflow pattern and transport process in operating rooms equipped with UCV systems and may find application in designing more effective ventilation strategies.
\end{abstract}

(C) 2020 Sharif University of Technology. All rights reserved.

\section{Introduction}

Surgical Site Infection (SSI) is one of the most common post-surgical complications. According to the Centers for disease control reports, SSI is the third most common nosocomial infection, averaging about 14$16 \%$ [1]. Furthermore, $2.6 \%$ of all surgeries suffer from SSI [2]. The risk of SSI significantly increases for more prolonged deep surgeries such as joint replacement.

*. Corresponding author. Tel.: +98216616 5522 E-mail addresses: bsajadi@ut.ac.ir (B. Sajadi); saman@sharif.edu (M.H. Saidi); gahmadi@clarkson.edu (G. Ahmadi).

doi: $10.24200 /$ sci. 2018.5514 .1359
Additional expenses due to SSI were estimated at about $\$ 5000$ in 1999 [2], costing the health care system in the US about $\$ 3.5$ billion per year [3].

It is well known that the most common pathogen that causes SSI is Staphylococcus aureus, which is responsible for $48 \%$ of all cases [2]. Staphylococcus aureus is a spherical bacterium that is naturally found in normal human skin. Staphylococcus aureus infections have become more challenging in recent decades due to the appearance of several antibiotic-persistent strands of the bacteria [3]. The primary source of Staphylococcus aureus is the flakes, which breaks away from the exposed skin of the surgical staff or the patient. Typically, these flakes are $25 \mu \mathrm{m}$ in diameter and $3-5 \mu \mathrm{m}$ in thickness. It was estimated that, during a two- to four-hour surgery, 1.15 to 90 million 
flakes were released [4], and about $5-10 \%$ of the flakes were contaminated with bacteria [5]. According to the authors [6], a surgeon, bending over the patient, may be a source of as many as 1000 airborne particles per minute. Furthermore, the distance of the surgical staff to the operating table affects the risk of wound contamination.

The risk of SSI depends on several factors including patient susceptibility to infection, surgical staff practices, operating room cleanliness, and the Heating, Ventilation and Air-Conditioning (HVAC) system [7]. Although health professionals have successfully used various techniques such as sterilizing surgical instruments, training the staff, using antibiotics, and developing the minimum invasive surgery methods to prevent the surgical wound from infection, SSI still occurs. Woods et al. [4] categorized the source of wound infection into (1) patient, (2) non-sterilized instruments, and (3) airborne bacteria. It is believed that most SSI cases result from airborne bacterial particles, which could be controlled by a properly designed ventilation system. To minimize the harmful microbiological agents responsible for the infection of surgical sites, cleanroom technology was applied to the ventilation of operating rooms in the $60 \mathrm{~s}$, which led to a considerable reduction in the number of postoperative SSIs [8]. Recent studies by Lidwell et al. [9], Charnley [10], and Ferrazzi et al. [11] on joint replacement, hip replacement, and cardiac surgeries respectively showed approximately $50 \%$ improvement in the wound infection control using a proper ventilation airflow pattern.

The classification of the operating room ventilation systems is similar to the cleanroom ones. Accordingly, the ventilation systems are categorized into (1) mixed or conventional and (2) unidirectional or laminar systems. Unidirectional systems, which are also known as Ultra-Clean Ventilation (UCV) systems [12], provide a protected clean area over a surgical table to minimize the transmission of airborne bacteria from a less clean area. The use of UCV systems has been recommended for surgical procedures, which deal with subcutaneous tissues or internal organs [13]. While the downward unidirectional ventilation system provides the most effective UCV systems, it has some disadvantages, one of which is the flow disturbed by upstream obstacles, especially surgical lights [14]. As a result, some other configurations such as horizontal [15], diagonal [16], differential [17], temperature-controlled [18], local [19], and portable [20] ones have been introduced. Numerical studies of Sadrizadeh et al. [21] showed that a proper ventilation scheme was highly dependent on internal obstacles and staff work practice.

Since the early $90 \mathrm{~s}$, with an improvement in the computational capacity of computers, Computational Fluid Dynamics (CFD) techniques have become an important engineering design tool for studying airflow and particle deposition in complex geometries [22-24]. The application of CFD for investigating indoor air quality in operating rooms has been reported in some pieces of research. Accordingly, the flow characteristics in an operating room depend on its geometry and door opening cycles [25], ambient temperature [26], supply inlets and return outlets configuration [27], inlet diffusers geometry [28], ventilation airflow rate [29], location of obstacles [30], surgeons posture [31], staff clothing [32], and their activity level [33]. The results of previous studies showed that the location of return outlets was not as important as the location of supply inlets [34,35]. Memarzadeh and Manning [7] suggested that the application of mixed high-low level outlets might lead to a better airflow distribution; however, the differences are not significant enough to make low- or high-level systems unreliable. Although the arrangement of supply inlets has considerable effect on the airflow pattern and the indoor air quality in conventionally ventilated environments, it appears that there is no concern regarding this issue in a UCV system, provided that the unidirectional zone covers the operating site and the surgical team. In the early $90 \mathrm{~s}$, Chen et al. [29] investigated airflow and contaminant dispersion in an operating room using the EulerianEulerian numerical approach. They concluded that increasing the ventilation airflow rate would lead to better air quality. The same conclusion was also reported by some others [36]. This intuitive result, however, runs contrary to some experimental data that suggested sometimes ventilation airflow increment does not show any improvement or even has negative effects on the wound infection rate $[37,38]$. It was suggested that this inconsistency between the computer model and the experimental data would result from treating the particulate phase as a scalar that ignores the physical nature of particles, affecting their transport and deposition [7]. As noted before, bacteria-carrying skin flakes are approximately $10 \mu \mathrm{m}$ in diameter. In this size, the particle inertia effects are important and Eulerian diffusion approach cannot reflect all aspects of the particle's behavior. Computational modeling of particle dispersion and deposition in passages with complex geometry was reported by $\mathrm{Li}$ et al. [39], Ahmadi and Smith [40], and Zhang and Ahmadi [41], among the others. Memarzadeh and Meanning [42] conducted extensive numerical studies to investigate the role of the operating room ventilation system in reducing the risk of infection in surgeries. Using the Eulerian-Lagrangian code, they concluded that the indoor air pattern was more important than the ventilation rate in preventing the wound from infection. They also found that, for the laminar airflow ventilation systems, there was an optimum value of $0.15 \mathrm{~m} / \mathrm{s}$ for the inlet air velocity beyond which the 
particle deposition on the wound increased due to the distortion of the protecting wound thermal plume [7]. This observation was also supported by Rui et al. [43] and Sajadi et al. [44]. In other words, while the ventilation airflow increment leads to a less contaminant concentration over the operating room, it does not necessarily decrease the risk of wound infection. Despite the fact that Memarzadeh and Manning's results are the basis for ASHRAE recommendations [45], the optimum inlet air velocity is not quite unique, as other standards suggest different values $[12,46]$. Previous studies have also reported that the surgical lamps have considerable influence on the airflow distribution all over an operating room due to both generation of a thermal plume and obstruction of the airflow [30]. Based on the results, the lights location [47] and their geometry [48] may remarkably affect the deposition of infectious airborne particles over the wound and should be considered in designing an effective ventilation system.

In this paper, the airflow distribution through an operating room and the resultant particle deposition over the wound are studied numerically. The effect of inlet air velocity and formation of a protecting thermal plume over the wound on the velocity distribution and airborne particles dispersion in the operating room is evaluated. Specific attention is paid to investigating the effect of surgical luminaries on the wound infection risk. The results of the present study provide a better understanding of the airflow pattern in the operating rooms and the effect of surgical lights on it so as to find more applications for developing more effective ventilation strategies to reduce infections after surgeries.

\section{Numerical method}

Figure 1 shows a schematic of the operating room model with a typical area of $37 \mathrm{~m}^{2}$ [49]. The arrangement of operating staff, equipment, and patients in the modeled room is done in accordance with DIN 4799 recommendations [50]. Due to a complex geometry of the model and room contents, an unstructured tetrahedral mesh is used to discretize the computational domain. A mesh with $1.8 \times 10^{6}$ cells is used for the computational analysis. The mesh density varies with a denser mesh in an ultra-clean area where gradients are predicted to be higher. A grid refinement was performed, and it was found that the mesh size used was sufficient to guarantee the independency of the results from the number of grids. For an incompressible fluid with heat transfer, the governing equations are as follows:

$$
\nabla\left(\rho V \phi-\Gamma_{\phi} \nabla \phi\right)=S_{\phi}
$$

where $V$ is the velocity vector, and the effective diffusion coefficient, $\Gamma_{\phi}$, and the source term, $S_{\phi}$, for different parameters, $\phi$, are listed in Table 1.

To resolve the turbulence closure problem, the RNG k- $\varepsilon$ model [51] accompanied by the standard wall function [52] is implemented to extract the turbulent properties due to its simplicity, robustness, and relatively accurate results [53]. The governing equations are solved on a collocated grid using ANSYS FLUENT

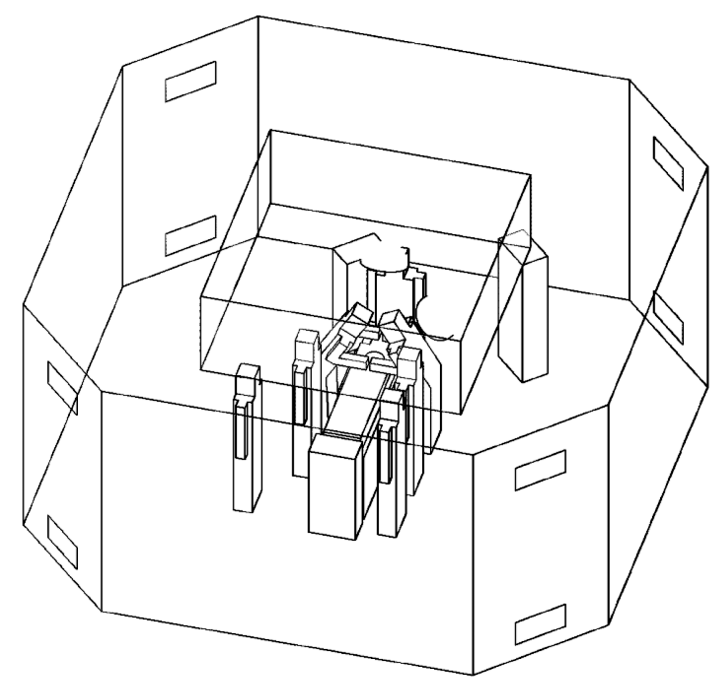

Figure 1. Geometric characteristics of the operating room model. Operating room: $6.3 \mathrm{~m} \times 6.3 \mathrm{~m} \times 3 \mathrm{~m}$ [49]; UCV system inlet: $2.8 \mathrm{~m} \times 2.8 \mathrm{~m}$ [12]; UCV system outlets, $0.6 \mathrm{~m} \times 0.3 \mathrm{~m}$; Surgical wound: $0.3 \mathrm{~m} \times 0.3 \mathrm{~m}$ [7]; for other dimensions and all distances, refer to DIN 4799 [50].

Table 1. Coefficients and source terms of the flow governing equations, Eq. (1).

\begin{tabular}{lccc}
\hline \multicolumn{1}{c}{ Equation } & $\boldsymbol{\phi}$ & $\boldsymbol{\Gamma}_{\boldsymbol{\phi}}$ & $\boldsymbol{S}_{\boldsymbol{\phi}}$ \\
\hline Continuity & 1 & - & - \\
Momentum & $V$ & $\mu_{\text {eff }}$ & $-\nabla p+\rho g \beta\left(T-T_{\infty}\right)$ \\
Energy & $c_{p} T$ & $\mu_{\text {eff }} / \mathrm{Pr}$ & - \\
Turbulent kinetic energy & $k$ & $\mu_{\text {eff }} / \sigma_{k}$ & $P_{k}-\rho \varepsilon$ \\
Turbulent kinetic energy & $\varepsilon$ & $\mu_{\text {eff }} / \sigma_{\varepsilon}$ & $\varepsilon\left(C_{1} P_{k}-C_{2} \varepsilon\right) / k$ \\
dissipation rate & & & \\
\hline
\end{tabular}

Note: $\mu_{e f f}=\mu+\mu_{t}, \mu_{t}=\rho C_{\mu} k^{2} / \varepsilon, C_{\mu}=0.0845, C_{1}=1.42, C_{2}=1.68$ 
12.1 commercial package [54]. Pressure-velocity coupling is established through SIMPLE algorithm [55], and all convection terms are discretized using a secondorder upwind scheme, which was found to provide acceptable accuracy in the indoor airflow modeling [56].

It is well known that the Eulerian-Eulerian approach is not appropriate for analyzing the motion of bacterial airborne particles due to their relatively large size [7]. Therefore, the Lagrangian trajectory analysis is implemented. The corresponding particle equation of motion is given as follows [44]:

$$
\frac{d u_{i}^{p}}{d t}=\frac{1}{\tau}\left(u_{i}-u_{i}^{p}\right)+g_{i}+n_{i}(t)
$$

where $u^{p}$ is the particle velocity, $g_{i}$ is the acceleration of gravity, $n_{i}$ is the Brownian force per unit mass, and $\tau$ is the particle relaxation time defined as follows:

$$
\tau=\frac{S d_{p}^{2} C_{c}}{18 \nu},
$$

where $d_{p}$ is the particle diameter, $S$ is the particleto-fluid density ratio, and Cunningham slip correction factor, $C_{c}$, is included to account for non-continuum effects. The Cunningham correction factor is given below:

$$
C_{c}=1 \mathrm{Kn}\left[1.257+0.4 \exp \left(-\frac{1.1}{\mathrm{Kn}}\right)\right],
$$

where Knudsen number, Kn, is:

$$
\mathrm{Kn}=\frac{2 \lambda}{d_{p}}
$$

where $\lambda$ is the air mean free path that equals $68 \mathrm{~nm}$ in the normal atmospheric conditions. Other forces, such as Saffman lift force, which are small, are neglected.

The turbulence diffusion that strongly affects particle transport in the indoor airflows needs to be properly estimated. In this study, the discrete random walk model is used to simulate the instantaneous, turbulent fluctuating velocity components. Accordingly, the fluctuating velocity is given below [18]:

$$
u_{i}^{\prime}=G \sqrt{\overline{u_{i}^{\prime 2}}}
$$

where $G$ is a Gaussian random number, and $\sqrt{\overline{u_{i}^{\prime 2}}}$ is the Root Mean Square (RMS) of the $i$ th fluctuating velocity component. For the $k-\varepsilon$ turbulence models, the mean square of fluctuating velocity components is equal to $2 / 3 k$.

The random number $G$ is updated using the eddy lifetime and the particle crossing time. The characteristic lifetime of turbulence eddies is as follows:

$$
\tau_{e}=2 T_{L},
$$

where $T_{L}$ is the turbulent Lagrangian time scale. For the $k-\varepsilon$ turbulence models, $T_{L}$ can be estimated as follows:

$$
T_{L}=0.15 \frac{k}{\varepsilon}
$$

The particle crossing time, the time a particle needs to pass across an eddy, is defined as follows:

$$
\tau_{c}=-\tau \operatorname{In}\left(1-\frac{L_{e}}{\tau\left|u-u_{p}\right|}\right),
$$

where $L_{e}$ is the eddy length scale.

The particle is assumed to interact with one eddy over the smaller values of $\tau_{e}$ and $\tau_{c}$; therefore, the random number $G$ is updated after the minimum of $\tau_{e}$ and $\tau_{c}$.

\subsection{Boundary conditions}

For the UCV system, constant velocity and constant temperature (typically $300 \mathrm{~K}$ ) inlet boundary conditions are used. At the outlets, all gradients are assumed to be zero. On the walls, the no-slip velocity boundary condition is used. A constant temperature of $300 \mathrm{~K}$ is used for the human (staff and patient) skin [14], except for the surgical wound where the temperature is assumed to be $310 \mathrm{~K}$, which is the core body temperature [7]. It is very common to use a constant heat flux boundary condition for the operating lights based on their power consumption. However, much of the power used by lights is transmitted via a radiation mechanism, which is not normally considered in indoor airflow investigations. Such simplification of the heat transfer mechanism modeling leads to the overprediction of the luminary surface temperature and the resultant thermal plume. In this study, a constant surface temperature of $350 \mathrm{~K}$ has been assumed for the surgical lights. This value is consistent with that of the earlier experimental studies reported by ADMECO AG [57]. The particles' behavior on the boundaries is also important for particle trajectory. In this study, it is assumed that particles are released from the wound with zero initial velocity. They are trapped in walls and exit the computational domain as they are reaching the outlet.

\section{Results and discussions}

Memarzadeh and Manning [7] suggested that only particles released close to the wound might lead to its contamination. In this study, to examine the effect of inlet air velocity on the wound infection, particles are released uniformly from $0.01 \mathrm{~m}^{3}$ volume over the wound and the percentage of particles deposited on the wound is evaluated. The density of particles is assumed to be similar to water, as bioaerosols are mostly made of water. The performed statistical independency study 


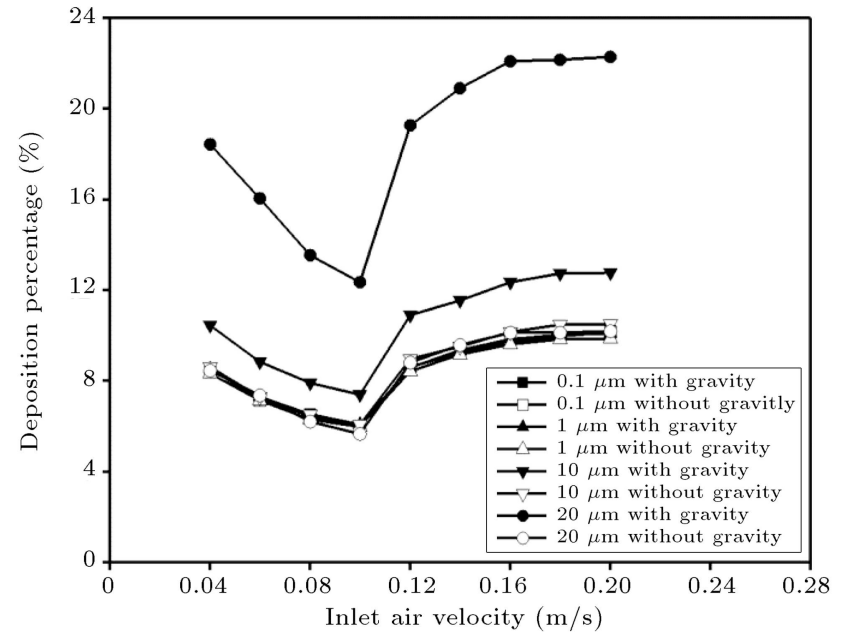

Figure 2. The effect of airflow inlet velocity and particle size on the deposition of particles over the wound.

showed that $10^{5}$ particles were necessary to ensure that the percentage of the deposited particles was independent of the number of released ones.

Figure 2 shows the effect of inlet air velocity and particle size on the percentage of particles that are deposited on the wound. It is seen that the deposition of particles is almost independent of the particle size in the range of 0.1 to $1 \mu \mathrm{m}$ and increases rapidly for the larger ones mainly due to gravity. The participation of the deposition mechanisms, including gravity and impaction, in the deposition of airborne particles on the wound is also presented in Figure 2. Due to a relatively large size of the studied particles, the effect of Brownian motion is almost negligible, and the main deposition mechanisms include only impaction and gravity force; the effect of the latter vanishes rapidly as the particle size goes under $1 \mu \mathrm{m}$. The deposition of particles due to impaction depends on not only the particle's concentration over the wound, but also the near wound distribution of airflow.

One interesting feature of the variation of deposition curves with velocity, shown in Figure 2 for different particle sizes, is that they all show an optimum value for the inlet air velocity that minimizes the deposition of particles. Furthermore, the optimum velocity is roughly independent of the particle size. The existence of the optimum airflow inlet velocity results from the formation of a thermal plume over the wound that acts as a protecting shield at low inlet velocities and is disturbed when the velocity goes over a certain limit. These features may be better understood by examining the near wound velocity and temperature distributions that are shown in Figure 3(a) and (b) for the inlet air velocities of $0.1 \mathrm{~m} / \mathrm{s}$ and $0.2 \mathrm{~m} / \mathrm{s}$, respectively. As illustrated in the above-mentioned figures, when the inlet velocity is sufficiently low, a thermal plume is formed on the wound due to the temperature difference between the wound tissue and the body skin. The thermal plume generates an upward flow over the wound, which protects it from infection caused by the deposition of airborne bacteria-carrying particles. Since the airflow inlet velocity increases over the optimal value, $0.1 \mathrm{~m} / \mathrm{s}$ in this case, the protecting thermal plume breaks down and the deposition of particles increases. As shown in Figure 4, the break of the wound thermal plume is also clearly detectable from the dispersion of particles when the airflow inlet velocity increases from $0.1 \mathrm{~m} / \mathrm{s}$ to $0.2 \mathrm{~m} / \mathrm{s}$. In addition, as can be seen in the figures, the direction of the dominant flow near the wound changes away from the wound towards the wound as the inlet air velocity increases over the optimum limit. It is known that impaction is the main mechanism that causes micro particles to deposit on the wound; thus, the amount of deposition depends on not only the concentration of particles over the wound, but also the near wound velocity distribution. As the inlet air velocity goes over the critical limit, airflow is predominantly directed towards the wound due to the break of the protecting thermal plume, and the deposition of particles increases considerably by the impaction effect. As a result, while the ventilation airflow in the operating rooms should be sufficiently high to remove particles from the wound area, it should not be too high to destroy the

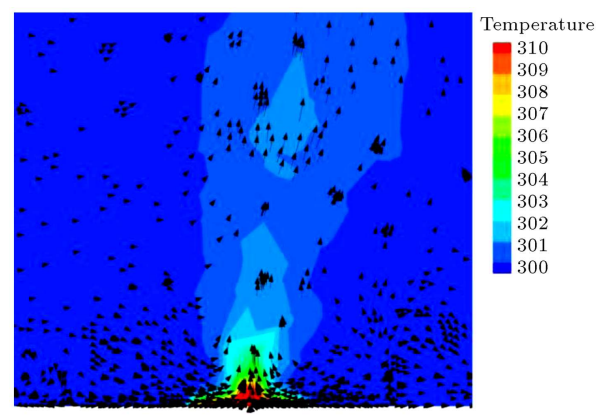

(a)

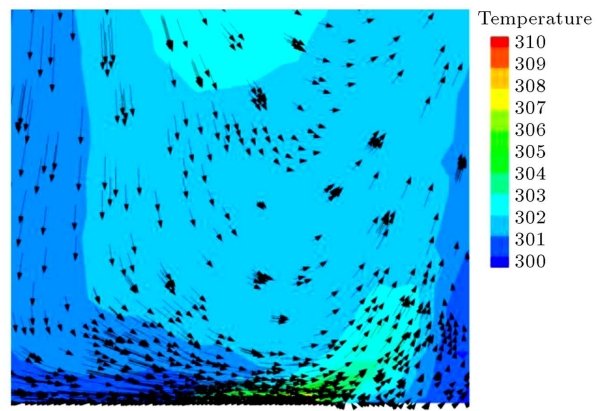

(b)

Figure 3. The effect of airflow inlet velocity on the near-wound velocity and temperature distributions: (a) $0.10 \mathrm{~m} / \mathrm{s}$ and (b) $0.20 \mathrm{~m} / \mathrm{s}$. 


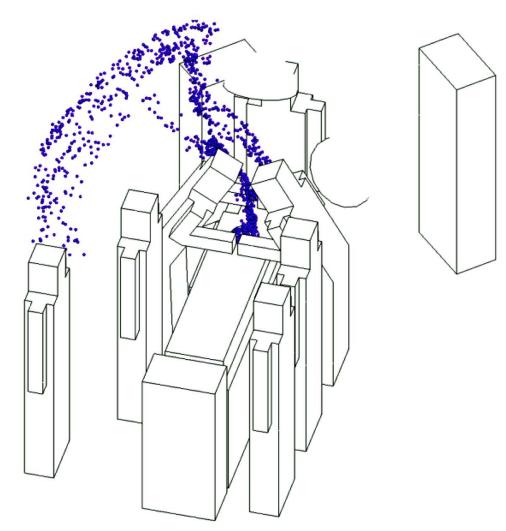

(a)

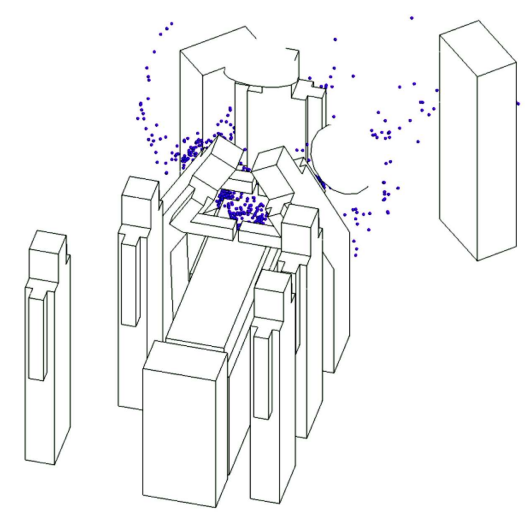

(b)

Figure 4. The effect of airflow inlet velocity on the airborne particles dispersion: (a) $0.1 \mathrm{~m} / \mathrm{s}$ and (b) $0.2 \mathrm{~m} / \mathrm{s}$.

protecting wound thermal plume and change the nearwound velocity direction towards the wound. These conflicting needs of operating rooms' ventilation system necessitate achieving an optimal value for the inlet air velocity of the UCV systems. In case of a too low inlet velocity, ventilation airflow is not sufficient to dilute the concentration of infectious airborne particles over the wound, and particles' deposition may be high. On the other hand, when the inlet airflow velocity is higher than the optimum value, the wound thermal plume breaks down and the deposition of particles increases due to the impaction effect, as noted before. As a result, there is an optimum airflow inlet velocity that minimizes the deposition of particles on the wound. Since the optimum velocity mainly depends on the near-wound velocity distribution, it is almost independent of the size of released particles, as indicated in Figure 2.

To further clarify the role of the protecting thermal plume in preventing the wound from airborne particles, a special case is simulated for which the wound temperature is equal to the skin temperature so that the thermal plume would not be formed. Figure 5

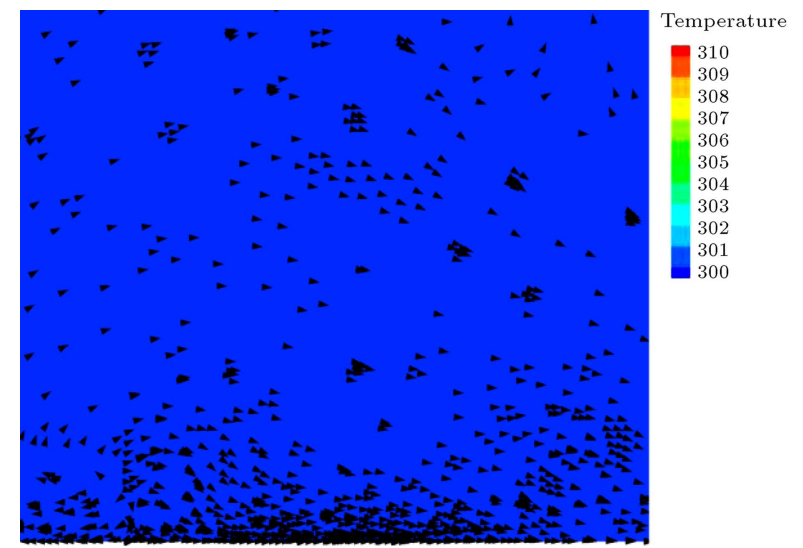

Figure 5. The effect of the wound thermal plume on the near-wound velocity and temperature distributions.

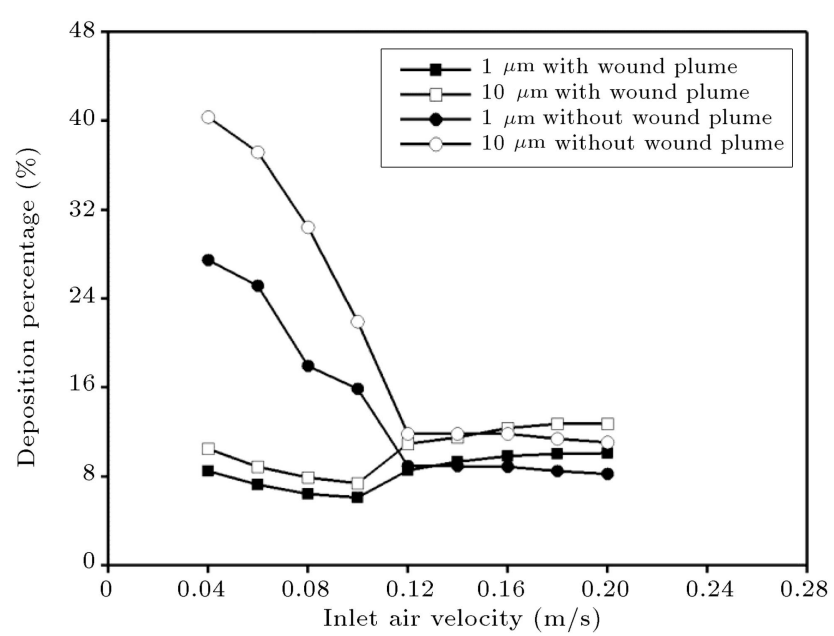

Figure 6. The effect of the wound thermal plume on the particle's deposition over the wound.

shows the velocity and temperature distributions near the wound in this case. It is seen that no plume is present and the airflow velocity is roughly directed towards the wound, which causes the contaminant particles to deposit on the wound due to impaction. To quantify the effect of the thermal plume, in Figure 6, the deposition curves for 1 and $10 \mu \mathrm{m}$ particles in the absence of the thermal plume are compared with the results of a case in which the thermal plume is formed. This figure indicates that without a temperature difference between the wound tissue and the body skin, the increase of the inlet air velocity decreases the deposition of particles monotonically due to the dilution of the particle concentration over the wound. In this case, there is no optimum value for the airflow inlet velocity for minimum deposition. Figure 6 , however, shows that the deposition of the particles decreases sharply with an increase in the inlet velocity up to about $0.12 \mathrm{~m} / \mathrm{s}$ and, then, remains roughly constant with a further increase in the inlet velocity. This implies that the effect of the wound thermal plume is more pronounced at low inlet 


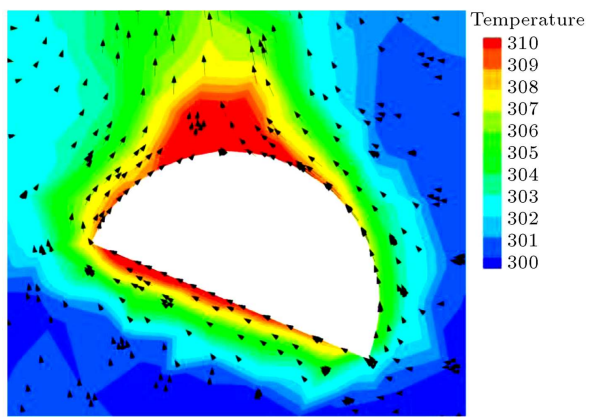

(a)

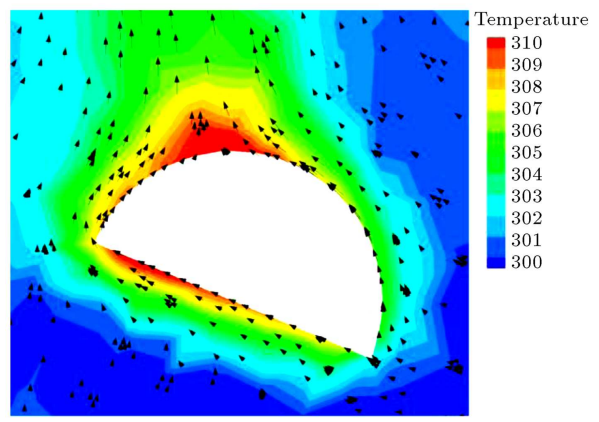

(c)

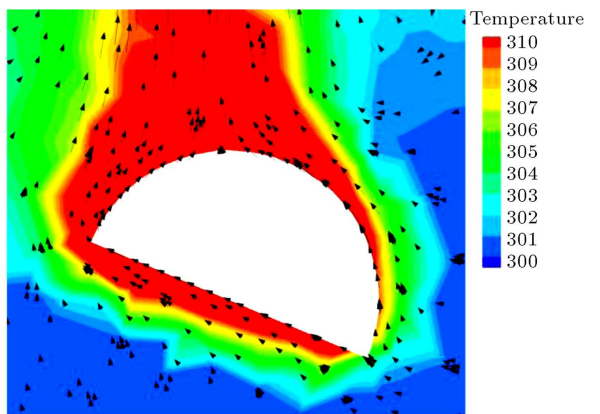

(b)

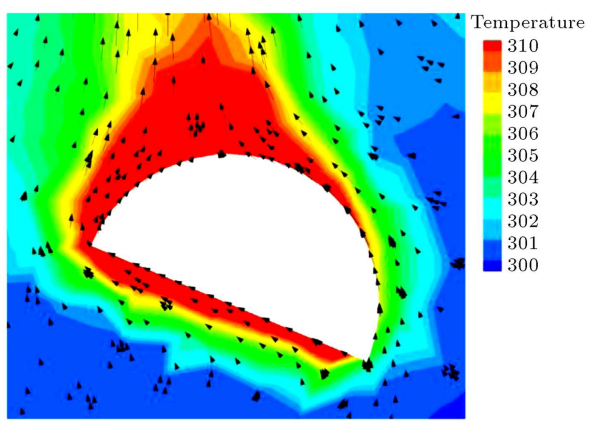

(d)

Figure 7. The effect of the surgical light boundary condition on the near lamp velocity and temperature distributions: (a) Constant temperature of $350 \mathrm{~K}$, (b) constant temperature of $400 \mathrm{~K}$, (c) constant heat flux of $100 \mathrm{~W}$, and (d) constant heat flux of $200 \mathrm{~W}$.

air velocities when it acts as a shield to protect the wound from the large deposition of infectious airborne particles. As the ventilation airflow becomes quite high, the effect of the wound thermal plume diminishes and the results become roughly the same for both cases.

Surgical luminary is one of the most important upstream obstacles in an operating room that can considerably influence the airflow pattern and the resultant particle dispersion due to both generation of an upward thermal plume and obstruction of the ventilation airflow. In the modeling, the strength of the thermal plume formed over the lamps mainly depends on the thermal boundary condition used for the light's surfaces. Figure 7 shows the effect of the surgical luminary boundary condition on the deposition of particles over the wound for two constant temperature boundary conditions of $350 \mathrm{~K}$ and $400 \mathrm{~K}$ and two constant heat flux ones of 100 Watts and 200 Watts. As depicted in the figure, the thermal boundary condition has considerable influence on the particle deposition curve, both on the deposition percentage values and on the optimum inlet air velocity. The negative effect of the generated thermal plume is so strong that it may increase the optimum inlet velocity up to $0.14 \mathrm{~m} / \mathrm{s}$. The influence of the surgical lights thermal plume on the indoor airflow pattern may be better described in Figure 8, which shows the velocity and temperature distributions near the lamps under various thermal conditions when the inlet air velocity

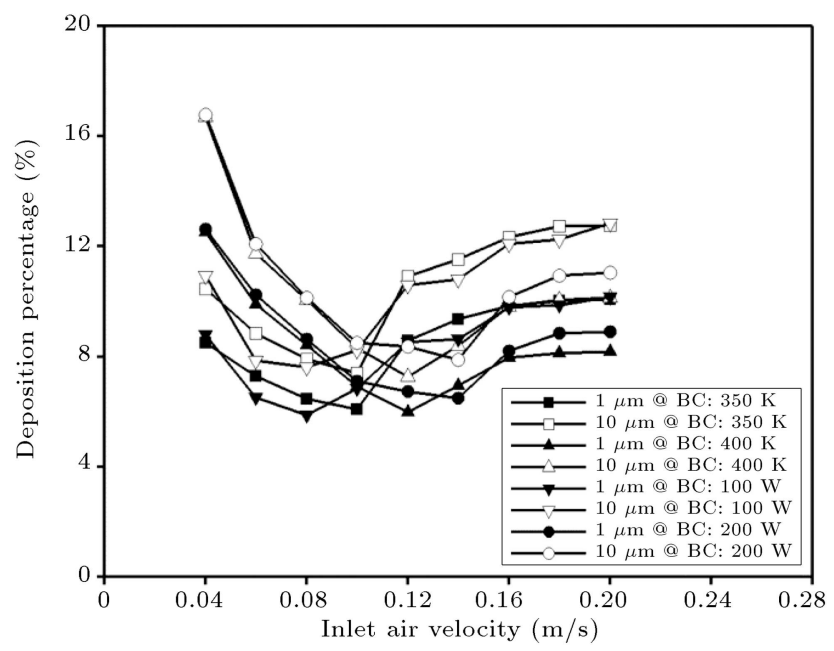

Figure 8. The effect of the surgical light boundary condition on the particle's deposition over the wound.

equals $0.10 \mathrm{~m} / \mathrm{s}$. As depicted in the figure, the thermal plume causes an upward flow over the lights that may disturb the upstream airflow pattern. To achieve the best ventilation performance, the inlet airflow should have enough momentum to overcome the upward flow, corresponding to the inlet air velocity of $0.14 \mathrm{~m} / \mathrm{s}$ for the case (c), which has the strongest thermal plume.

Besides the thermal plume generated over the lights that may disturb the upstream airflow, a surgical lamp may also directly act as an obstacle and block the ventilation airflow. In this respect, the shape of 
a luminary and its location considerably influence the airflow pattern and the dispersion of infectious airborne particles. The effect of the location and geometry of surgical lamps on the wound infection risk can be better described in Figure 9, which shows the percentage of $10 \mu \mathrm{m}$ particles deposited over the wound. As depicted in the figure, although the luminary shape and location have almost no major influence on the optimum inlet air velocity, the improper location of a light may considerably increase the deposition of particles, even up to $100 \%$. Independency of the optimum inlet velocity from the geometry and location of the lamps results mainly from the fact that these parameters have negligible influence on the near wound velocity and temperature distributions, and they are almost similar to those shown in Figure 3(a). This feature indicates that the geometric characteristics of luminaries are not as important as their thermal characteristics in impressing the wound thermal plume and changing optimum ventilation air velocity, accordingly. Unfavorable influences resulting from the surgical lamp location may be remarkably controlled using lights with a well-designed geometry. The important point is that the position of lights is almost out of a ventilation expert responsibility, and it is usually adjusted by a surgeon to properly illumine the surgical wound. As a consequence, the design of the ventilation system should be made in such a way as to minimize the negative effects resulting from adjustment of lamp location by the surgical staff.

A new method to improve the air quality under UCV systems is using partitions over the surgical zone, as proposed by National Health Service (NHS) [12]. However, the effects of the partitions on the airflow distribution and the dispersion of particles through operating rooms have not been evaluated in detail, to the best of authors' knowledge. As shown in Figure

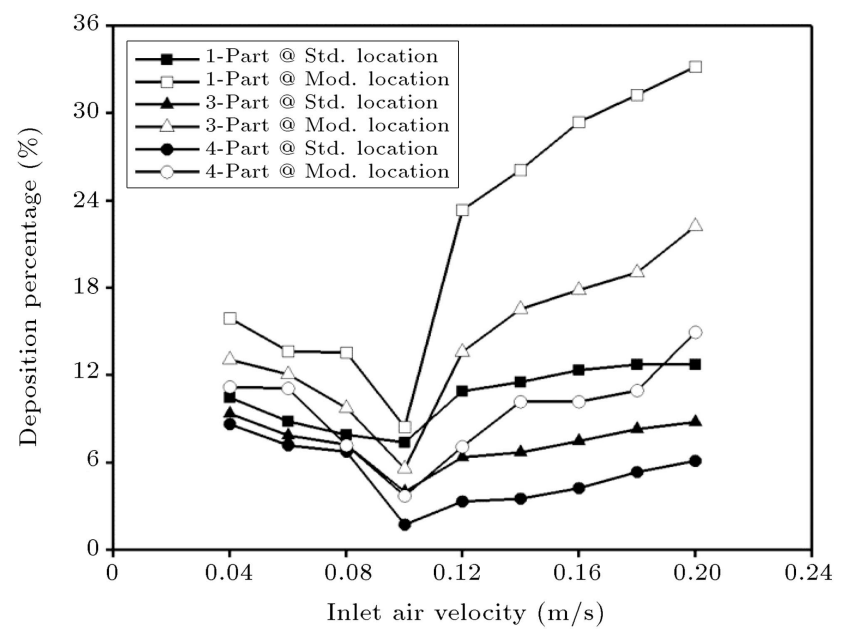

Figure 9. The effect of geometric characteristics of the surgical lights on the particle's deposition over the wound.

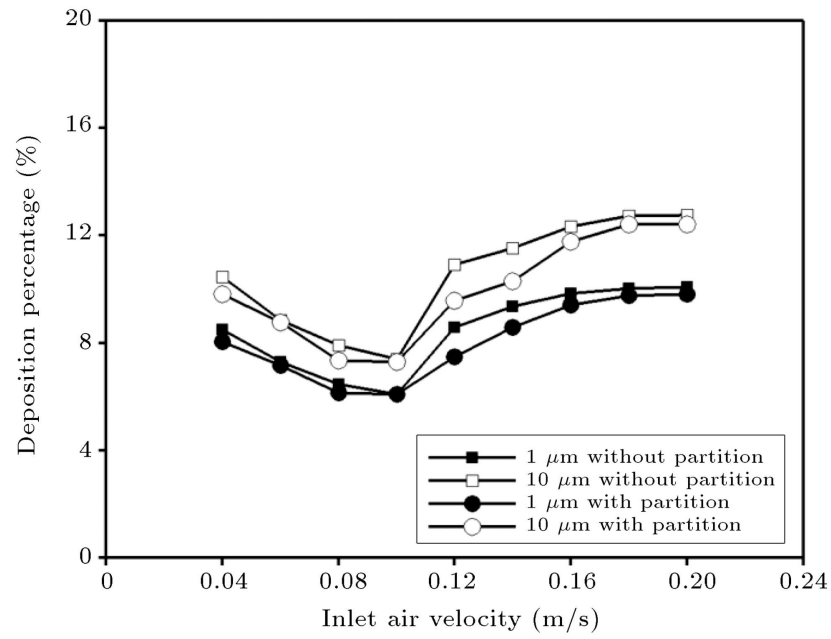

Figure 10. The effect of the partitions on the particle's deposition over the wound.

1 , the partitions are $1 \mathrm{~m}$ in height and are mounted around the ultra-clean area, either permanently or temporarily. The main effect of the partitions is to direct the ventilation airflow towards the surgical table and prevent its momentum from decay due to expansion effect. As a consequence, the concentration of particles over the wound is diluted and their deposition decreases accordingly. However, this feature is not strong enough to impose any considerable effect on the wound thermal plume and the near-wound temperature, and velocity distributions are almost similar to those in Figure 3(a). Quantitative effect of using the partitions on the particle's deposition may be extracted referring to the deposition curves in Figure 10. As presented in the figure, the installation of the partitions decreases the deposition of airborne particles on the wound due to providing a cleaner environment over the wound. However, the partitions have no considerable effect on the optimum inlet air velocity, as discussed previously, by looking at the near-wound velocity and temperature distribution.

\section{Conclusions}

In this study, the effects of the Ultra-Clean Ventilation (UCV) system characteristics on the performance of the operating room ventilation system and on the risk of wound infection were investigated numerically. The results may be summarized as follows:

1. Due to a relatively large size of the studied particles, the contribution of Brownian motion in the particle's deposition is almost negligible. Accordingly, the main deposition mechanisms are impaction and gravitational sedimentation, while the effect of the latter vanishes rapidly as the particle size goes below $1 \mu \mathrm{m}$;

2. The formation of a thermal plume over the wound 
due to the temperature difference between the wound tissue and the body skin causes an optimum value for the inlet air velocity, which minimizes the deposition of the particles. Over the optimum inlet velocity, the protecting thermal plume is destroyed and the deposition of particles increases because of impaction effect;

3. Specification of the surgical luminaries has considerable effect on the wound infection risk and on the optimum inlet air velocity both due to the generation of an upward thermal plume and the obstruction of the ventilation airflow. However, the thermal characteristics of the lamps are more critical than their geometric characteristics in impressing the airflow pattern and the deposition of airborne particles over the wound. The negative effects of the improper location of a surgical lamp can be minimized using luminaries with a welldesigned geometry;

4. Mounting partitions in the UCV systems decreases the percentage of deposited particles over the wound and may reduce the risk of wound infection. However, its effect on the near-wound velocity and temperature distribution is not strong enough to have a remarkable influence on the wound thermal plume and on the optimum inlet air velocity.

\section{Acknowledgement}

The financial support of this research, provided by Iran National Science Foundation (INSF), under grant number 88000620 is greatly appreciated.

\section{References}

1. Malone, D., Genuit, T., Tracy, J.K., et al. "Surgical site infections: reanalysis of risk factors", Journal of Surgical Research, 103, pp. 89-95 (2002).

2. Kirkland, K., Briggs, J.P., Trivette, S.L., et al. "The impact of surgical-site infections in the 1990s: attributable mortality, excess length of hospitalization, and extra costs", Infection Control and Hospital Epidemiology, 20, pp. 725-730 (1999).

3. Stevenson, T.C., Experimental Investigation of Hospital Operating Room Air Distribution (M.Sc. Thesis), Georgia Institute of Technology, Atlanta, GA (2008).

4. Woods, J.E., Brayman, D., Rasmussen, R.W., et al. "Ventilation requirements in hospital operating rooms - Part I: Control of airborne particles", ASHRAE Transactions, 92, pp. 396-426 (1996).

5. Noble, W.C. "Dispersal of bacteria from human skin", International Symposium on Contamination Control, Copenhagen, Denmark (1976).

6. Zamunar, N. "Operating room environment with turbulent airflow", ASHRAE Technical Data Bulletin,
Hospital and Operating Room Ventilation, pp. 101-107 (1986).

7. Memarzadeh, F. and Manning, A. "Reducing risks of surgery", ASHRAE Journal, 45, pp. 28-33 (2003).

8. Turner, R.S. "Laminar air flow", Journal of Bone and Joint Surgery, 56, pp. 430-435 (1974).

9. Lidwell, O.M., Elson, R.A., Lowbury, E.J., et al. "Ultra clean air and antibiotics for prevention of postoperative infection: A multi-center study of 8052 joint replacement operations", Acta Orthopaedica Scandinavica, 58, pp. 4-13 (1987).

10. Charnley, J. "Postoperative infection after total hip replacement with special reference to air contamination in the operating room", Clinical Orthopedics, 87, pp. 167-187 (1972).

11. Ferrazzi, P., Allen, R., Crupi, G., et al. "Reduction of infection after cardiac surgery: A clinical trial", Annuals of Thoracic Surgery, 42, pp. 321-325 (1986).

12. "Health technical memorandum 2025: ventilation in healthcare premises", National Health Service (NHS) Estates, London, UK (1994).

13. Humphreys, H., Stacey, A.R., and Taylor, E.W. "Survey of operating theatres in Great Britain and Ireland", Journal of Hospital Infection, 30, pp. 245252 (1995).

14. Chow, T.T. and Yang, X.Y. "Performance of ventilation system in a non-standard operating room", Building and Environment, 38, pp. 1401-1411 (2003).

15. Liu, J., Wang, H., and Wen, W. "Numerical simulation on a horizontal airflow for airborne particles control in hospital operating room", Building and Environment, 44, pp. 2284-2289 (2009).

16. Woloszyn, M., Virgone, J., and Stephane, M. "Diagonal air distribution system for operating rooms experiment and modeling", Building and Environment, 39, pp. 1171-1178 (2004).

17. Romano, F., Marocco, L., Gusten, J., et al. "Numerical and experimental analysis of airborne particles control in an operating theater", Building and Environment, 89, pp. 369-379 (2015).

18. Wang, C., Holmberg, S., and Sadrizadeh, S. "Numerical study of temperature-controlled airflow in comparison with turbulent mixing and laminar airflow for operating room ventilation", Building and Environment, 144, pp. 45-56 (2018).

19. Loomans, M.G.L.C., de Visser, I.M., Loogman, J.G.H., et al. "Alternative ventilation system for operating theaters: Parameter study and full-scale assessment of the performance of a local ventilation system", Building and Environment, 102, pp. 26-38 (2016).

20. Sadrizadeh, S. and Holmberg, S. "Effect of a portable ultra-clean exponential airflow unit on the particle distribution in an operating room", Particuology, 18, pp. 170-178 (2015). 
21. Sadrizadeh, S., Holmberg, S., and Tammelin, A. "A numerical investigation of vertical and horizontal laminar airflow ventilation in an operating room", Building and Environment, 82, pp. 517-525 (2014).

22. Ahmadi, G. and Li, A. "Computer simulation of particle transport and deposition near a small isolated building", Journal of Wind Engineering \& Industrial Aerodynamics, 84, pp. 23-46 (2000).

23. Shams, M., Ahmadi, G., and Smith, D.H. "Computational modeling of flow and sediment transport and deposition in meandering rivers", Advances in Water Resources, 25, pp. 689-699 (2002).

24. Nazridoust, K. and Ahmadi, G. "Airflow and pollutant transport in street canyons", Journal of Wind Engineering \& Industrial Aerodynamics, 94, pp. 491-522 (2006).

25. Sadrizadeh, S., Pantelic, J., Sherman, M., et al. "Airborne particle dispersion to an operating room environment during sliding and hinged door opening", Journal of Infection and Public Health, 11, pp. 631635 (2018).

26. Ufat, H., Kaynakli, O., Yamankaradeniz, N., et al. "Investigation of the number of particles in an operating room at different ambient temperatures and inlet velocities", International Journal of Ventilation, 17, pp. 209-223 (2018).

27. Eslami, J., Abbassi, A., Saidi, M.H., et al. "Effect of supply/exhaust diffuser configurations on the contaminant distribution in ultra clean environments: Eulerian and Lagrangian approaches", Energy and Buildings, 127, pp. 648-657 (2016).

28. Pourfarzaneh, A., Jafarian, A., and Kharinezhad Arani, H. "Numerical study of particulate turbulent flow to investigate recovery period in cleanrooms", Scientia Iranica, 26(1) pp. 331-345 DOI: 10.24200/ SCI.2018.20322 (2019).

29. Chen, Q., Zhai, J., and Moser, A. "Control of airborne particle concentration and draught risk in an operating room", Indoor Air, 2, pp. 154-167 (1992).

30. Zoon, W.A.C., var der Heijden, M.G.M., Hensen, J.L.M., et al. "Influence of the shape of surgical lights on the disturbance of the airflow", Proceedings of the 11th International Roomvent Conference, Busan, South Korea (2009).

31. Sadrizadeh, S., Afshari. A., Karimipanah, T., et al. "Numerical simulation of the impact of surgeon posture on airborne particle distribution in a turbulent mixing operating theatre", Building and Environment, 110, pp. 140-147 (2016).

32. Sadrizadeh, S. and Holmberg, S. "Surgical clothing systems in laminar airflow operating room: a numerical assessment", Journal of Infection and Public Health, 7, pp. 508-516 (2014).
33. Sadrizadeh, S., Tammelin, A., Ekolind, P., et al. "Influence of staff number and internal constellation on surgical site infection in an operating room", Particuology, 13, pp. 42-51 (2014).

34. Murakami, S., Kato, S., and Suyama, Y. "Numerical and experimental study on turbulence diffusion fields in conventional clean rooms", ASHRAE Transactions, 94, pp. 469-493 (1988).

35. Murakami, S., Kato, S., and Suyama, Y. "Numerical study of diffusion field as affected by arrangement of supply and exhaust openings in conventional flow type clean room", ASHRAE Transactions, 95, pp. 113-127 (1989).

36. Chow, T.T. and Yang, X.Y. "Ventilation performance in the operating theatre against airborne infection: numerical study on an ultra-clean system", Journal of Hospital Infection, 59, pp. 138-147 (2005).

37. Humphreys, H. and Taylor, E.W. "Operating theatre ventilation standards and the risk of postoperative infection", Journal of Hospital Infection, 50, pp. 85-90 (2002).

38. Salvati, E.A. "Infection rates after 3,175 total hip and total knee replacements performed with and without a horizontal unidirectional filtered airflow system", Journal of Bone and Joint Surgery, 64, pp. 525-535 (1982).

39. Li, A., Ahmadi, G., Bayer, R.G., et al. "Aerosol particle deposition in an obstructed turbulent duct flow", Journal of Aerosol Science, 25, pp. 91-112 (1994).

40. Ahmadi, G. and Smith, D.H. "Particle transport and deposition in a hot-gas cleanup pilot plant", Aerosol Science and Technology, 29, pp. 183-205 (1998).

41. Zhang, H. and Ahmadi, G. "Aerosol particle transport and deposition in vertical and horizontal turbulent duct flows", Journal of Fluid Mechanics, 406, pp. 5588 (2000).

42. Memarzadeh, F. and Manning, A. "Comparison of operating room ventilation systems in the protection of the surgical site", ASHRAE Transactions, 108, pp. $3-5$ (2002).

43. Rui, Z., Guangnei, T., and Jihong, L. "Study on biological contaminant control strategies under different ventilation models in hospital operating room", Building and Environment, 43, pp. 793-803 (2008).

44. Sajadi, B., Saidi, M.H., and Ahmadi, G. "Numerical evaluation of the operating room ventilation performance: Ultra-clean ventilation (UCV) systems", Scientia Iranica, 26(4), pp. 2394-2406 (2019). DOI: 10.24200/SCI.2018.5431.1269

45. HVAC Design Manual for Hospitals and Clinics, ASHRAE, Atlanta, GA (2003).

46. Guidelines for Design and Construction of Hospitals and Health Care Facilities, AIA, Washington, DC (2006). 
47. Chow, T.T., Lin, Z., and Bai, W. "The integrated effect of medical lamp position and diffuser discharge velocity on ultra-clean ventilation performance in an operating theatre", Indoor and Built Environment, 15, pp. 315-331 (2006).

48. Zoon, W.A.C., var der Heijden, M.G.M., Loomans, M.G.L.C., et al. "On the applicability of the laminar flow index when selecting surgical lighting", Building and Environment, 45, pp. 1976-1983 (2010).

49. "MPROG 287: Healthcare facilities - Guidelines for mechanical installations", MPROG, Tehran, Iran (2006).

50. "DIN 4799: Heating, ventilation and air conditioning - testing of air distribution systems serving operating theatres", DIN, Berlin, Germany (1990).

51. Yakhot, V., Orszag, S.A., Thangam, S., et al. "Development of turbulence models for shear flows by a double expansion technique", Physics of Fluids A, 4, pp. 1510-1520 (1992).

52. Launder, B.E. and Spalding, D.B. "The numerical computation of turbulent flows", Computer Methods in Applied Mechanics and Engineering, 3, pp. 269-289 (1974).

53. Chen, Q. "Comparison of different $k-\varepsilon$ models for indoor airflow computations", Numerical Heat Transfer: Part B, 28, pp. 353-369 (1995).

54. "ANSYS FLUENT 12.1 User's Guide", ANSYS Inc., Canonsburg, PA (2009).

55. Patankar, S.V., Numerical Heat Transfer and Fluid Flow, Hemisphere Publishing Corporation, New York: NY (1980).
56. Davidson, L. and Fontaine, J.R. "Calculation of the flow in a ventilated room using different finite difference schemes and different treatments of the walls", Proceeding of the 4th CLIMA 2000 Conference, Sarajevo, Yugoslavia (1989).

57. "ADMECO-LUX. Instructions for fitting and use", ADMECO AG, Hochdorf, Switzerland (2003).

\section{Biographies}

Behrang Sajadi is an Assistant Professor in School of Mechanical Engineering at University of Tehran, Iran. His current research interests include aerosol mechanics, indoor air quality, energy modeling, heat transfer enhancement in refrigeration systems, and novel HVAC and refrigeration systems.

Mohammad Hassan Saidi is a Professor in School of Mechanical Engineering at Sharif University of Technology, Iran. His current research interests include MEMS, heat transfer enhancement in boiling and condensation, modeling of pulse tube refrigeration, vortex tube refrigerators, indoor air quality and clean room technology, energy efficiency in home appliances, and desiccant cooling systems.

Goodarz Ahmadi is a Professor of Mechanical and Aeronautical Engineering at Clarkson University, NY. He has been awarded the title of "Clarkson Distinguished Professor". Some of his research interests include multiphase and granular flows, three-phase slurry flows, aerosols, micro-contamination control, turbulence modeling, stability of fluid motions, continuum mechanics, nonlinear random vibrations, and earthquake engineering. 